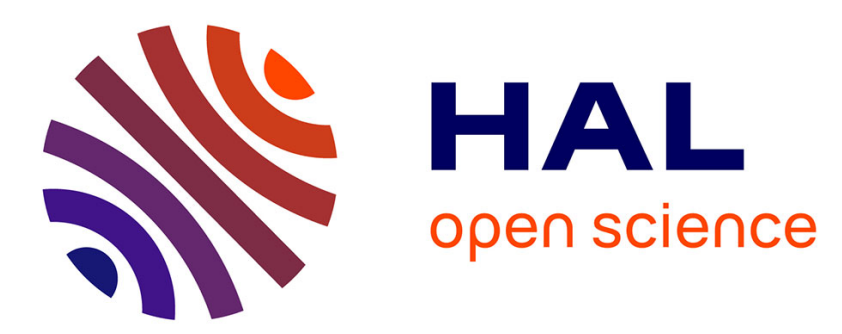

\title{
Effect of rare-earth doping on the free-volume structure of Ga-modified Te20As30Se50 glass
}

Ya. Shpotyuk, A. Ingram, O. Shpotyuk, Catherine Boussard-Plédel, Virginie Nazabal, Bruno Bureau

\section{- To cite this version:}

Ya. Shpotyuk, A. Ingram, O. Shpotyuk, Catherine Boussard-Plédel, Virginie Nazabal, et al.. Effect of rare-earth doping on the free-volume structure of Ga-modified Te20As30Se50 glass. RSC Advances, 2016, 6 (27), pp.22797-22802. 10.1039/c6ra02092e. hal-01298761

HAL Id: hal-01298761

https://hal-univ-rennes1.archives-ouvertes.fr/hal-01298761

Submitted on 31 May 2016

HAL is a multi-disciplinary open access archive for the deposit and dissemination of scientific research documents, whether they are published or not. The documents may come from teaching and research institutions in France or abroad, or from public or private research centers.
L'archive ouverte pluridisciplinaire HAL, est destinée au dépôt et à la diffusion de documents scientifiques de niveau recherche, publiés ou non, émanant des établissements d'enseignement et de recherche français ou étrangers, des laboratoires publics ou privés. 


\title{
Effect of rare-earth doping on free-volume structure of Ga-modified $\mathrm{Te}_{20} \mathrm{As}_{30} \mathrm{Se}_{50}$ glass
}

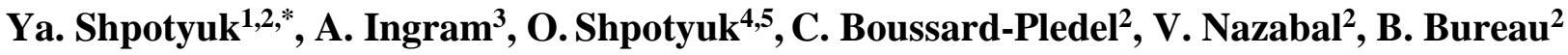 \\ ${ }^{1}$ Centre for Innovation and Transfer of Natural Sciences and Engineering Knowledge, \\ University of Rzeszow, 1, Pigonia str., 35-959 Rzeszow, Poland \\ ${ }^{2}$ Lab. Verres et Céramiques UMR-CNRS 6226, University of Rennes 1,35042 Rennes Cedex, France \\ ${ }^{3}$ Opole University of Technology, 75, Ozimska str., 45370 Opole, Poland \\ ${ }^{4}$ Vlokh Institute of Physical Optics, 23, Dragomanov str., 79005 Lviv, Ukraine \\ ${ }^{5}$ Institute of Physics, Jan Dlugosz University, 13/15, Armii Krajowej al., 42200 Czestochowa, Poland \\ *The corresponding author e-mail: yashpotyuk@gmail.com
}

\begin{abstract}
By exploring positron-electron annihilation technique in positron lifetime measuring mode, it is shown that principal rare-earth (RE) induced structural reconfiguration in Ga-codoped TAS-235 glass (that is glassy $\mathrm{Te}_{20} \mathrm{As}_{29} \mathrm{Ga}_{1} \mathrm{Se}_{50}$ alloy) is related to occupation of intrinsic free-volume voids by embedded RE ions tightly connected with Ga-based tetrahedrons via strong covalent RE-Se/Te-Ga links. Gradual decrease in the intensity of second component of two-term decomposed lifetime spectra of annihilating positrons accompanied with detectable increase in defect-related positron lifetime (thus inducing essentially depressed rate in positron trapping) is evidenced at the example of $\operatorname{Pr}^{3+}$ ions added homogeneously to $\mathrm{Te}_{20} \mathrm{As}_{2} \mathrm{Ga}_{1} \mathrm{Se}_{50}$ glass in the amount of 500 ppmw. Observed changes in positron lifetime spectra are explained in terms of competitive contribution of different occupancy positions in Ga-codoped glass available for RE ions and trapped positrons.
\end{abstract}

\section{Introduction}

Rare-earth (RE) doping in IR-transmitting chalcogenide glasses (ChG) is of high importance as promising technological resolution to produce perspective mid-IR laser sources for compact photonics. $^{1-6}$ So development of high reliable structure-sensitive tool for identification and characterization of RE doping attracts a great attention in photonics research community dealing with implementation of new functional media.

In contrast to oxide glasses, where a large variety of experimental techniques can be employed to study RE doping (such as nuclear magnetic and electron paramagnetic resonances, neutron diffraction, fluorescence line-narrowing and decay analysis), ${ }^{7,8}$ the structural probes to be successfully applied to ChG are very restricted. In order to ensure optimum low phonon energy environment for positively charged RE-ions, the ChG should be additionally modified by local negatively charged sites, which act like cation vacancies in crystals providing a total electrical charge compensation. ${ }^{8}$ Because of anomalously high electronegativity proper to oxygen $\mathrm{O}$ atom, ${ }^{9}$ an intrinsic atomic arrangement in oxide glasses can be adapted respectively to create own electrical charge misbalance needed to accommodate homogeneously the embedded RE ions without their clustering (and thus to overcome a parasitic concentration quenching of fluorescence). ${ }^{6-8}$ In $\mathrm{ChG}$, which are characterized by close electronegativities for constituting atoms, the RE-incorporation induced structural reconfiguration cannot be simply over-balanced by intrinsic covalent-bonded atomic environment obeying full saturation in respect to the Mott's $8-\mathrm{N}$ rule. ${ }^{9}$ Charge-compensation equilibrium in such a case is achieved only extrinsically, e.g. by additional sites randomly distributed in a glass matrix possessing locally uncompensated excess of negative electrical charge. In this respect, the $\mathrm{ChG}$ preliminary doped 
with Ga or In seem most efficient, ${ }^{6,10-15}$ where charge compensation for incorporated RE ions is satisfied due to local over-coordinated environment around these atoms whatever their main valence state. Under a given rate of these codopants, which do not disturb the glass-forming ability of the hosting ChG, the RE ions can reside homogeneously without forming tightly bounded atomic clusters. ${ }^{8}$ Thus, the most efficient structural tools to probe successful RE doping in ChG should be sensitive to hierarchical atomistic transformations squeezing (Ga,In)-codoped and RE-doped sites.

That is why the phenomenon of positron-electron annihilation in positron lifetime measuring mode, e.g. positron annihilation lifetime (PAL) spectroscopy known as high-informative free-volume probing method suitable for different solids despite their structural nature, ${ }^{16,17}$ is expected to be useful to characterize RE-doping in ChG. Indeed, the positron (the positive antiparticle of electron) can be imagined as highly electropositive probe in its interaction with matter, whatever the nature of the interaction (trapping in extended defects or due to decaying of bound positron-electron states known as positronium Ps atoms in structurally-intrinsic voids). ${ }^{16,17}$ Under condition of atomic-accessible free volume in $\mathrm{Ga} / \mathrm{In}$-modified $\mathrm{ChG}$, the negatively charged sites related to incorporated codopants are most preferential occupancy positions for both positrons and RE-ions. So competitive contribution from corresponding annihilation paths parameterized through histogram of elementary positronelectron annihilation events forming PAL spectrum, is expected as numerical measure of RE doping.

In this research, the method of PAL spectroscopy will be first employed to study structural changes in Ga-modified TAS-235 glass (the known glassy-like $\mathrm{Te}_{20} \mathrm{As}_{30} \mathrm{Se}_{50}$ alloy widely used in IR chalcogenide photonics) caused by doping with $\mathrm{Pr}^{3+}$ ions. ${ }^{18-21}$

\section{Experimental}

The studied ChG alloys of parent $\mathrm{Te}_{20} \mathrm{As}_{30} \mathrm{Se}_{50}$ (TAS-235), Ga-codoped $\mathrm{Te}_{20} \mathrm{As}_{29} \mathrm{Ga}_{1} \mathrm{Se}_{50}$ and this glass further doped with $500 \mathrm{ppmw}$ of $\operatorname{Pr}^{3+}$ ions were prepared from high-purity elemental precursors, e.g. Ga $(7 \mathrm{~N})$, As $(5 \mathrm{~N}), \mathrm{Se}(5 \mathrm{~N}), \mathrm{Te}(6 \mathrm{~N})$ and $\mathrm{Pr}_{2} \mathrm{Se}_{3}(3 \mathrm{~N})$, the ingredients being specially purified by distillation with low evaporation rate to remove impurities such as $\mathrm{O}, \mathrm{C}, \mathrm{H}_{2} \mathrm{O}$, and $\mathrm{SiO}_{2}$. Appropriate amounts of ingredients with total weight close to $30 \mathrm{~g}$ were put into silica tube of $10 \mathrm{~mm}$ diameter. Then, the ampoules were sealed under a vacuum and heated to $650{ }^{\circ} \mathrm{C}$ with $2^{\circ} \mathrm{C} / \mathrm{min}$ rate in a rocking furnace for $10 \mathrm{~h}$ with further quenching in water from $500^{\circ} \mathrm{C}$. To remove mechanical strains appeared during rapid quenching, the alloys were annealed during $6 \mathrm{~h}$ at temperature of $10^{\circ} \mathrm{C}$ less than glass transition $\left(\sim 120^{\circ} \mathrm{C}\right)$. The obtained rods were cut into $\sim 1.5 \mathrm{~mm}$ thick disks and polished. A more detailed description of samples preparation can find elsewhere. ${ }^{20-22}$ The glassy state and high purity of the samples prepared were confirmed by XRD measurements showing wide-stretched halos typical for amorphous state and absence of any impurity-related signatures in the IR absorption spectra. ${ }^{20}$

The PAL measurements were performed using a fast-fast coincidence system of $230 \mathrm{ps}$ resolution (the full width at half maximum of single Gaussian determined by measuring ${ }^{60} \mathrm{Co}$ isotope) based on two Photonis XP2020/Q photomultiplier tubes coupled to $\mathrm{BaF}_{2}$ scintillator 25.4A10/2M-QBaF-X-N detectors (Scionix, Bunnik, Holland) and ORTEC ${ }^{\circledR}$ electronics (ORTEC, Oak Ridge, TN, USA). The reliable PAL spectra were detected in a normal-measurement statistics ( $\sim 1 \mathrm{M}$ coincidences) under stabilized temperature $\left(22^{\circ} \mathrm{C}\right)$ and relative humidity $(35 \%)$. The channel width of $6.15 \mathrm{ps}$ allows a total number of channels to be 8000 . The radioactive ${ }^{22} \mathrm{Na}$ isotope of relatively low $\sim 50 \mathrm{kBq}$ activity prepared from aqueous solution of ${ }^{22} \mathrm{NaCl}$ wrapped by Kapton ${ }^{\circledR}$ foil (DuPont ${ }^{\mathrm{TM}}$, Circleville, OH, USA) of $12 \mu \mathrm{m}$ thickness was used as positron source sandwiched between two identical tested samples.

The raw PAL spectra were processed with LT 9.0 program. ${ }^{23}$ Accepting unchanged contribution intensity from a source with two inputs (with 372 ps and $\sim 2$ ns lifetimes), these spectra were adequately decomposed into two components with $\tau_{1,2}$ lifetimes and normalized $I_{1,2}$ intensities $\left(I_{1}+I_{2}=1\right)$. Under above spectrometer resolution, this allows an error-bar for such arranged measuring protocol not worse than $\pm 0.005 \mathrm{~ns}$ in lifetimes and \pm 0.01 in intensities. Introducing third component in the envelope of fitting curves did not improve goodness of fitting significantly. So Ps formation is not proper for studied ChG in full agreement with previous results. ${ }^{21}$ The positron trapping modes, e.g. average positron lifetime $\tau_{a v}$, lifetime in defect-free bulk $\tau_{b}$, trapping rate in defects $\kappa_{d}$ and fraction of trapped positrons $\eta$ were calculated exploring a formalism of known two-state positron trapping model. ${ }^{16,17,21,24-26}$ In addition, the $\left(\tau_{2}-\tau_{b}\right)$ difference was accepted as a size measure for extended free- 
volume defects where positrons were trapped, as well as the $\tau_{2} / \tau_{b}$ ratio was taken as direct signature of nature of these trapping defects in terms of equivalent number of monovacancies. ${ }^{16}$

\section{Results and discussion}

The PAL characteristics of pure TAS-235 $\left(\mathrm{Te}_{20} \mathrm{As}_{30} \mathrm{Se}_{50}\right)$ glass and Ga-modified partiallycrystallized $\mathrm{Te}_{20} \mathrm{As}_{30-\mathrm{x}} \mathrm{Ga}_{\mathrm{x}} \mathrm{Se}_{50}$ alloys $(\mathrm{x}=2,5)$ were preliminary studied in previous work. ${ }^{21}$ The changes observed in positron trapping modes under crystallization were ascribed to appearance of cubic $\mathrm{Ga}_{2} \mathrm{Se}_{3}$ phase, the explanation being given in terms of agglomeration of intrinsic free-volume voids under the same chemical environment in glass and partially crystallized states. It was also shown that TAS-235 glass doped with 1 at. $\%$ of Ga added instead of As (within $\mathrm{Te}_{20} \mathrm{As}_{30-\mathrm{x}} \mathrm{Ga}_{\mathrm{x}} \mathrm{Se}_{50}$ cutsection) is not subjected to any devitrification influences, forming suitable host matrix for further REdoping. ${ }^{20,22}$ In this research, the $\mathrm{Te}_{20} \mathrm{As}_{29} \mathrm{Ga}_{1} \mathrm{Se}_{50}$ glass was used as parent matrix for doping with 500 ppmw of $\operatorname{Pr}^{3+}$ ions.

The PAL spectra of both parent and $\mathrm{Pr}^{3+}$-doped $\mathrm{Te}_{20} \mathrm{As}_{29} \mathrm{Ga}_{1} \mathrm{Se}_{50}$ glass reconstructed from $\mathrm{x} 2-$ component fitting at the general background of standard source contribution are respectively depicted on Fig. 1a and 1b. The limited values of statistical scatter of variance tightly grouped around 0-axis testify that PAL measurements are adequately described within this fitting procedure. So the decaying behavior of PAL spectra on Fig. 1 can be reflected by sum of two exponents with different time constants inversed to positron lifetimes. ${ }^{16}$ The best-fit positron trapping modes for these samples along with experimental data for TAS-235 glass calculated within two-state model are given in Table 1.

It is obvious that Ga-codoping does not cause increase in defect-specific positron lifetime $\tau_{2}$ (like under crystallization), ${ }^{21}$ but rather leads to an opposite and very slight decaying tendency (decrease from $0.360 \mathrm{~ns}$ in TAS-235 glass to $0.358 \mathrm{~ns}$ in Ga-codoped $\mathrm{Te}_{20} \mathrm{As}_{29} \mathrm{Ga}_{1} \mathrm{Se}_{50}$ glass). In contrast, the intensity of second component $I_{2}$ is subjected to more pronounced changes, e.g. rough dropping, thus resulting in gradual decrease in positron trapping rate in defects $\kappa_{d}$ and, correspondingly, the fraction of trapped positrons $\eta$ (Table 1). It means that Ga-codoping does not approach fragmentation of free-volume voids in TAS-235 glass as it occurs in crystallized $\mathrm{Te}_{20} \mathrm{As}_{28} \mathrm{Ga}_{2} \mathrm{Se}_{50}$ alloy. ${ }^{21}$

Then, it is found that doping of $\mathrm{Te}_{20} \mathrm{As}_{29} \mathrm{Ga}_{1} \mathrm{Se}_{50}$ glass with 500 ppmw of $\mathrm{Pr}^{3+}$ further depresses the process of positron trapping (in part, the $\kappa_{d}$ and $\eta$ values are respectively reduced to $0.64 \mathrm{~ns}^{-1}$ and $0.14)$, this tendency being realized via more essential increase in defect-related positron lifetime $\tau_{2}$ (from $0.358 \mathrm{~ns}$ to $0.363 \mathrm{~ns}$ ) accompanied by strong decrease in $I_{2}$ intensity (from 0.370 to 0.330 ). Noteworthy, neither defect-free bulk positron lifetime $\tau_{b}$, nor average positron lifetime $\tau_{a v}$. are subjected to detectable changes (within an error-bar of PAL measurements) in these successive Gacodoping and $\mathrm{Pr}^{3+}$-doping processes. Let's clarify physical meaning of these structural reconfiguration processes grounded on previous results for similar chalcogenide glass-forming systems. ${ }^{20-22,26-30}$

Thus, it is well justified that among huge diversity of expected positron trapping sites possible in different $\mathrm{ChG}$ matrices, the preferential process of positron capturing is defined by extended freevolume defects in the nearest vicinity of chalcogen atoms neighboring with main glass-forming structural units (network-composing polyhedrons). ${ }^{26-30}$ In view of extra-low two-fold coordination and strong directionality of covalent bonding, the chalcogen atoms form low-electron density spaces, termed also as bond free solid angles (BFSA) by Kastner. ${ }^{31}$ Such BFSA undoubtedly contribute to neighboring geometrical free-volume spaces, ensuring them to possess an effective negative electrical charge due to proximity with more electronegative chalcogen atom $(\mathrm{Ch}=\mathrm{S}, \mathrm{Se}, \mathrm{Te})$ linked with more electropositive cation-type neighbor (As). The $\mathrm{Ch}$ atoms form an outer wall for innermost free-volume voids, which can be identified in view of their preferential electric state as counterparts of cation vacancies in crystals. Therefore, the most efficient positron traps in $\mathrm{ChG}$ can be imagined as geometrical voids within cycle-type formations of Ch-interlinked polyhedrons, such as $\mathrm{As}(\mathrm{Se} / \mathrm{Te})_{3 / 2}$ pyramids, surrounded preferentially by Se- and/or Te-based BFSA. These voids are composed of atomic-accessible geometrical cores arrested by surrounding atomic-inaccessible shells formed by Seand/or Te-based BFSA.

Specifically, in the case of chalcogen-rich TAS-235 glass (as compared with stoichiometric ChG built of corner-shared $\mathrm{As}(\mathrm{Se} / \mathrm{Te})_{3 / 2}$ pyramids $),{ }^{18-21}$ an essential contribution of-Se-Se- bridges between pyramids somewhat depresses the positron trapping like in Se-rich glassy As-Se. ${ }^{28}$ But just 
these homonuclear links can be affected by small Ga additions, as it follows from energetic balance of covalent chemical bonding in quaternary Ga-As-Se-Te system (see Table 2), composed by assuming the homonuclear Ga-Ga, As-As, Se-Se and Te-Te bond energies as $34.1 \mathrm{kcal} / \mathrm{mol}, 32.1 \mathrm{kcal} / \mathrm{mol}, 44.0$ $\mathrm{kcal} / \mathrm{mol}$ and $33.0 \mathrm{kcal} / \mathrm{mol}$, respectively, ${ }^{32-34}$ and calculating the heteronuclear bond energies in respect to known Pauling method. ${ }^{32}$ Thus, in view of this analysis and in excellent agreement with previous structure study, ${ }^{20}$ it follows that $\mathrm{GaSe}_{4 / 2}$ tetrahedrons (not $\mathrm{GaTe}_{4 / 2}$ ) mostly appear in TAS-235 glass under $\mathrm{Ga}$ codoping instead of homonuclear $\mathrm{Ch}-\mathrm{Ch}$ (e.g. Se-Se, Se-Te and/or Te-Te) links. So corner-sharing polyhedrons directly linked through common $\mathrm{Ch}$ atom become dominating building blocks in $\mathrm{Te}_{20} \mathrm{As}_{29} \mathrm{Ga}_{1} \mathrm{Se}_{50}$ glass, respectively modifying an arrangement of free-volume voids.

Following to well-known graphical presentation of idealized structure of RE-doped Ge-As-S glass given by Aitken, ${ }^{12}$ this specificity of free-volume arrangement in TAS-235 glass can be presented as shown on Fig. 2a. The pyramidal $\mathrm{AsSe}_{3 / 2}$, AsTe $3 / 2$ and mixed $\mathrm{As}(\mathrm{Se} / \mathrm{Te})_{3 / 2}$ units interlinked directly through common $\mathrm{Ch}$ atom ( $-\mathrm{Se}-$ and/or $-\mathrm{Te}-$ bridges) or through two $\mathrm{Ch}$ atoms (e.g. $-\mathrm{Se}-\mathrm{Se}-,-\mathrm{Se}-\mathrm{Te}-$ and/or $-\mathrm{Te}-\mathrm{Te}-$ bridges) create characteristic cycle-type arrangement with some amount of positron trapping sites in the form of agglomerated inner free-volume voids. Under transition to Ga-codoped $\mathrm{Te}_{20} \mathrm{As}_{29} \mathrm{Ga}_{1} \mathrm{Se}_{50}$ glass, the Ga-based $\mathrm{GaSe}_{4 / 2}$ polyhedrons with energetically favorable Ga-Se bonds (Table 2) appear in the network of interlinked As(Se/Te) $3 / 2$ pyramids (Fig. 2b). In preferential Ch environment (as in TAS-235 glass), the Ga behaves as typical metal tending to be four-fold coordinated by $\mathrm{Ch}$ atoms to form mostly $\mathrm{GaSe}_{4 / 2}$ tetrahedrons (despite its main valence state +3 ), as it was well argued in previous research. ${ }^{20}$ From charge compensation standpoint, it means that some excess of negative electrical charge is stabilized in a vicinity of these tetrahedrons. Created deficit in $\mathrm{Ch}$ is counterbalanced by disappearing of some $-\mathrm{Se}-\mathrm{Se}-,-\mathrm{Se}-\mathrm{Te}-$ and $-\mathrm{Te}-\mathrm{Te}-$ bridges at the cost of direct corner-shared links between polyhedrons. Under small amount of Ga added (not too far to disturbed preferential ring statistics in a glassy network), these structural reconfiguration processes do not change essentially the volume of existing positron traps (at least, near average atomic coordination 2.3 character for TAS-235, where rather smooth compositional dependence of defectrelated positron lifetime $\tau_{2}$ is expected for glassy As-Se). ${ }^{26,28,35}$ Disappearing of some two-atomic $\mathrm{Ch}-\mathrm{Ch}$ - bridges along with formation of $\mathrm{GaSe}_{4 / 2}$ tetrahedrons makes cycle-type formations in glassy $\mathrm{Te}_{20} \mathrm{As}_{29} \mathrm{Ga}_{1} \mathrm{Se}_{50}$ narrower (Fig. 2b), and free-volume voids arrested by interlinked polyhedrons become respectively smaller resulting in slightly reduced defect-related positron lifetime $\tau_{2}$ (Table 1). So network of Ga-codoped glass becomes denser. Indeed, as it follows from Archimedes displacement measurements (in a distilled water with $\pm 0.005 \mathrm{~g} / \mathrm{cm}^{3}$ error-bar), the atomic density of glassy $\mathrm{Te}_{20} \mathrm{As}_{29} \mathrm{Ga}_{1} \mathrm{Se}_{50}$ reaches $4.912 \mathrm{~g} / \mathrm{cm}^{3}$ instead of $4.888 \mathrm{~g} / \mathrm{cm}^{3}$ for TAS-235 glass (thus giving in recalculation to molar volume, correspondingly, $17.80 \mathrm{~cm}^{3} / \mathrm{mol}$ and $\left.17.90 \mathrm{~cm}^{3} / \mathrm{mol}\right){ }^{21}$

Such densification of atomic structure of $\mathrm{Te}_{20} \mathrm{As}_{2} \mathrm{Ga}_{1} \mathrm{Se}_{50}$ glass shifts balance between available positron annihilation paths from defect-specific trapping towards defect-free bulk trapping. Under such condition, the intensity of second component $I_{2}$ is not further a good parameter, describing realistic concentration of positron traps (since positron trapping now is essentially disturbed by increased probability of annihilation from bulk defect-free states). Even under unchanged defect-free bulk positron lifetime $\tau_{b}$, which can be caused by counterbalanced inputs from changes in positron annihilation channels, this effect leads to depressed trapping rate in defects $\kappa_{d}$ and fraction of trapped positrons $\eta$, as it is demonstrated in Table 1.

Effect of RE-doping on PAL modes in such modified structure of Ga-codoped $\mathrm{Te}_{20} \mathrm{As}_{29} \mathrm{Ga}_{1} \mathrm{Se}_{50}$ glass can be explained in terms of competitive contribution of changed occupancy positions available for RE ions and trapped positrons. Such free-volume sites possessing simultaneously an effective negative electrical charge are placed in a vicinity of Ga-based tetrahedrons as schematically illustrated in Fig. 2b. The $\mathrm{Pr}^{3+}$ ions are stabilized in the network of $\mathrm{Te}_{20} \mathrm{As}_{29} \mathrm{Ga}_{1} \mathrm{Se}_{50}$ glass due to strong covalent bridging $\mathrm{Pr}^{3+}-\mathrm{Se} / \mathrm{Te}-\mathrm{Ga}$ links, ${ }^{7,8,12}$ thus eliminating corresponding void as potential positron trapping center (Fig. 2c). Thereby, the depressed positron trapping in $\mathrm{Te}_{20} \mathrm{As}_{29} \mathrm{Ga}_{1} \mathrm{Se}_{50}$ glass doped with 500 ppmw of $\operatorname{Pr}^{3+}$ (as it demonstrated by positron trapping modes gathered in Table 1) results from changed occupancy of these Ga-related free-volume positron traps.

As to the concentration of these extended positron trapping sites, it can be roughly estimated by accepting their analogy with negatively charged vacancies in elemental and compound semiconductors giving trapping coefficient at the level of $10^{15}$ atom $\cdot \mathrm{s}^{-1} \cdot 36,37$ With atomic densities and experimental 
trapping rates character for different glasses in Table 1 , it gives defect concentration near $5 \cdot 10^{16} \mathrm{~cm}^{-3}$. Of course, these defects can be affected by RE additions even at such low level as a few tens of ppmw, provided the same sites are responsible for RE occupation and positron trapping. Undoubtedly, just this specificity is most essential in application of PAL spectroscopy to study RE doping effects in $\mathrm{ChG}$, especially in a view that conventional atomic structure sensitive probes (X-ray, electron or neutron diffraction) are ineffective because of under-margin level of added ions, which is typically beyond reliably detectable limits of these methods. ${ }^{7,8}$ Noteworthy unchanged $\left(\tau_{2}-\tau_{b}\right)$ difference and $\tau_{2} / \tau_{b}$ ratio (see Table 1) testify also in a favor of the same nature for positron traps in all studied ChG.

\section{Conclusions}

The PAL spectroscopy in positron lifetime measuring mode treated in terms of two-state trapping model was utilized firstly to study effect of $500 \mathrm{ppmw}$ of $\mathrm{Pr}^{3+}$ ions doping on free-volume structure of Ga-modified $\mathrm{Te}_{20} \mathrm{As}_{30} \mathrm{Se}_{50}$ (TAS-235) glass. The positron trapping is shown to be mostly depressed in Ga-codoped glassy $\mathrm{Te}_{20} \mathrm{As}_{29} \mathrm{Ga}_{1} \mathrm{Se}_{50}$, this process occurring without essential changing in the volume of positron trapping defects. Appearance of $\mathrm{GaSe}_{4 / 2}$ tetrahedrons based on energetically favorable Ga-Se bonds possessing local excess of negative electrical charge within network of interlinked $\mathrm{As}(\mathrm{Se} / \mathrm{Te})_{3 / 2}$ pyramids is expected as principal response in the structure of this glass, the created deficit in chalcogen being counterbalanced by disappearing of some two-atomic chalcogen bridges at a cost of direct corner-sharing links between polyhedrons. It is found that doping of $\mathrm{Te}_{20} \mathrm{As}_{29} \mathrm{Ga}_{1} \mathrm{Se}_{50}$ glass with $500 \mathrm{ppmw}$ of $\mathrm{Pr}^{3+}$ further depresses the positron trapping, this tendency being realized via more detectable increase in defect-related positron lifetime and strong decrease in $I_{2}$ intensity. This effect is explained in terms of competitive contribution of different occupancy positions available for RE ions and trapped positrons. The $\mathrm{Pr}^{3+}$ ions are stabilized in network of $\mathrm{Te}_{20} \mathrm{As}_{29} \mathrm{Ga}_{1} \mathrm{Se}_{50}$ glass in vicinity of $\mathrm{GaSe}_{4 / 2}$ tetrahedrons due to strong bridging $\mathrm{Pr}-\mathrm{Se} / \mathrm{Te}-\mathrm{Ga}$ links, thus eliminating respective free-volume voids as potential positron traps.

\section{Acknowledgements}

This research is supported by POLONIUM common actions program for years 2015-2016 realized in respect to bilateral Agreement on scientific-technical cooperation between Polish and French governments from 1966.

\section{References}

1. B.J. Eggleton, B. Luther-Davies and K. Richardson, Nat. Photonics, 2011, 5, 141-148.

2. J.-L. Adam, X. Zhang (Eds.), Chalcogenide Glasses: Preparation, Properties and Applications, Woodhead Publishing, Oxford, Cambridge, New Dehli, 2014.

3. S. Cui, R. Chahal, Ya. Shpotyuk, C. Boussard, J. Lucas, F. Charpentier, H. Tariel, O. Loreal, V. Nazabal, O. Sire, V. Monbet, Z. Yang, P. Lucas and B. Bureau, Proc. SPIE, 2014, 8938, 893805-1-9.

4. B. Bureau, X. Zhang, F. Smektala, J.-L. Adam, J. Troles, H. Ma, C. Boussard-Pledel, J. Lucas, P. Lucas, D. Le Coq, M.R. Riley and J.H. Simmons, J. Non-Cryst. Solids, 2004, 345-346, 276-283.

5. A.B. Seddon, Z. Tang, D. Furniss, S. Sujecki and T.M. Benson, Opt. Express, 2010, 18, 2670426719.

6. E.R. Barney, Z. Tang, A. Seddon, D. Furniss, S. Sujecki, T. Benson, N. Neate and D. Gianolio, RSC Adv., 2014, 4, 42364-42371.

7. T.H. Lee, S.I. Simdyankin, L. Su and S.R. Elliott, Phys. Rev. B, 2009, 79, 180202-1-4.

8. T.H. Lee, S.I. Simdyankin, J. Hegedus, J. Heo and S.R. Elliott, Phys. Rev. B, 2010, 81, 104204-1-6.

9. A. Feltz, Amorphous and vitreous inorganic solids, Mir, Moscow, 1986.

10. B. Cole, L.B. Shaw, P.C. Pureza, R. Mossadegh, J.S. Sanghera and I.D. Aggarwal, J. Non-Cryst. Solids, 1999, 256-257, 253-259.

11. J. Hu, C.R. Menyuk, C. Wei, B. Shaw, J.S. Sanghera and I.D. Aggarwal, Opt. Lett., 2015, 40, 3687-3690.

12. B.G. Aitken, C.W. Ponader and R.S. Quimby, C.R. Chimie, 2002, 5, 865-872.

13. M.F. Churbanov, I.V. Scribachev, V.S. Shiryaev, V.G. Plotnichenko, S.V. Smetanin, E.B. Kryukova, Yu.N. Pyrkov and B.I. Galagan, J. Non-Cryst. Solids, 2013, 326-327, 301-305. 
14. R. Golovchak, Ya. Shpotyuk, V. Nazabal, C. Boussard-Pledel, B. Bureau, J. Cebulski and H. Jain, J. Chem. Phys., 2015, 142, 184501-1-10.

15. R. Golovchak, Ya. Shpotyuk, C.M. Thomas, V. Nazabal, C. Boussard-Pledel, B. Bureau, H. Jain. Peculiarities of $\mathrm{Ga}$ and Te incorporation in glassy arsenic selenides // Journal of Non-Crystalline Solids 429 (2015) 104-111.

16. R. Krause-Rehberg and H. Leipner, Positron annihilation in semiconductors: defect studies, Springer, Heidelberg, 1999.

17. Y.C. Jean, P.E. Mallon and D.M. Schrader, Principles and Application of Positron and Positronium Chemistry, World Sci. Publ. Co. Pte. Ltd., New Jersy-London-Singapore-Hong Kong, 2003.

18. G. Delazir, M. Dussauze, V. Nazabal, P. Lecante, M. Dolle, P. Rozier, E.I. Kamitsos, P. Jovari and B. Bureau, J. Alloys Compd., 2011, 509, 831-836.

19. P. Jovari, B. Bureau, I. Kaban, V. Nazabal, B. Beuneu and U. Rutt, J. Alloys Compd., 2009, 488, 39-43.

20. Ya. Shpotyuk, B. Bureau, C. Boussard-Pledel, V. Nazabal, R. Golovchak, P. Demchenko and I. Polovynko, J. Non-Cryst. Solids, 2014, 398-399, 19-25.

21. O. Shpotyuk, A. Ingram, B. Bureau, Ya. Shpotyuk, C. Boussard-Pledel, V. Nazabal and R. Szatanik, J. Phys. Chem. Solids, 2014, 75, 1049-1053.

22. Ya. Shpotyuk, C. Boussard-Pledel, V. Nazabal, R. Chahal, J. Ari, B. Pavlyk, J. Cebulski, J.L. Doualan and B. Bureau, Opt. Mater., 2015, 46, 228-232.

23. J. Kansy, Nucl. Instrum. Methods Phys. Res., Sect. A, 1996, 374, 235-244.

24. F. Tuomisto and I. Makkonen, Rev. Mod. Phys., 2013, 85, 1583-1631.

25. A. Seeger, Appl. Phys., 1974, 4, 183-199.

26. O. Shpotyuk and J. Filipecki, Free volume in vitreous chalcogenide semiconductors: possibilities of positron annihilation lifetime study, WSP, Czestochowa, 2003.

27. M. Hyla, J. Filipecki, O. Shpotyuk, M. Popescu and V. Balitska, J. Optoelectron. Adv. Mater., 2007, 9, 3177-3181.

28. A. Ingram, R. Golovchak, M. Kostrzewa, S. Wacke, M. Shpotyuk and O. Shpotyuk, Physica B, 2012, 407, 652-655.

29. O. Shpotyuk, R. Golovchak, A. Ingram, V. Boyko and L. Shpotyuk, Phys. Status Solidi C, 2013, 10, 117-120.

30. O.I. Shpotyuk, J. Filipecki and V.O. Balitska, J. Optoelectron. Adv. Mater., 2008, 10, 3193-3197.

31. M. Kastner, Phys. Rev. B, 1973, 7, 5237-5252.

32. L. Pauling, The nature of the chemical bond, Cornell Univ. Press, New York, 1960.

33. J. Bicerano and S.R. Ovshinsky, J. Non-Cryst. Solids, 1985, 74, 75-84.

34. L. Tichy and H. Ticha, J. Non-Cryst. Solids, 1995, 189, 141-146.

35. O.K. Alekseeva, V.I. Mihajlov and V.I. Shantarovich, Phys. Status Solidi A, 1978, 48, K169-K173.

36. R. Krause-Rehberg and H.S. Leipner, Appl. Phys. A, 1997, 64, 457-466.

37. P. Hautojarvi, Mater. Sci. Forum, 1995, 175-178, 47-58. 
Table 1. Fitting parameters and positron trapping modes describing two-term reconstructed PAL spectra of glassy $\mathrm{Te}_{20} \mathrm{As}_{30} \mathrm{Se}_{50},{ }^{21}$ as well as parent and $\mathrm{Pr}^{3+}$-doped (500 ppmw) $\mathrm{Te}_{20} \mathrm{As}_{29} \mathrm{Ga}_{1} \mathrm{Se}_{50}$.

\begin{tabular}{|c|c|c|c|c|c|c|c|c|c|}
\hline \multirow{3}{*}{ Sample, state } & \multicolumn{3}{|c|}{ Fitting parameters } & \multicolumn{6}{|c|}{ positron trapping modes } \\
\hline & $\tau_{1}$ & $\tau_{2}$ & $I_{2}$ & $\tau_{a v}$ & $\tau_{b}$ & $\kappa_{d}$ & $\tau_{2}-\tau_{b}$ & $\tau_{2} / \tau_{b}$ & $\eta$ \\
\hline & ns & ns & a.u. & ns & ns & $\mathrm{ns}^{-1}$ & ns & - & - \\
\hline $\begin{array}{l}\text { Te20As30Se50 } \\
Z=2.30 ; \rho=4.888 \mathrm{~g} / \mathrm{cm}^{3}\end{array}$ & 0.202 & 0.360 & 0.400 & 0.264 & 0.244 & 0.86 & 0.12 & 1.47 & 0.17 \\
\hline $\begin{array}{l}\text { Te20As29Ga1Se50 } \\
\mathrm{Z}=2.30 ; \rho=4.912 \mathrm{~g} / \mathrm{cm}^{3}\end{array}$ & 0.208 & 0.358 & 0.370 & 0.263 & 0.246 & 0.75 & 0.11 & 1.44 & 0.16 \\
\hline $\begin{array}{l}\text { Te20As29Ga1Se50 + 500 ppm } \text { Pr }^{3+} \\
\mathrm{Z}=2.30 ; \rho=4.910 \mathrm{~g} / \mathrm{cm}^{3}\end{array}$ & 0.213 & 0.363 & 0.330 & 0.262 & 0.246 & 0.64 & 0.12 & 1.47 & 0.14 \\
\hline
\end{tabular}

Table 2. Mean molar energies $E(\mathrm{kcal} / \mathrm{mol})$ of covalent bonds in Ga-codoped TAS-235 glass.

\begin{tabular}{|c|c|c|c|}
\hline Bond & $E, \mathrm{kcal} / \mathrm{mol}$ & Bond & $E, \mathrm{kcal} / \mathrm{mol}$ \\
\hline Ga-Ga & 34.1 & As-Se & 41.7 \\
\hline As-As & 32.1 & As-Te & 32.7 \\
\hline Se-Se & 44.0 & Ga-Se & 55.2 \\
\hline Te-Te & 33.0 & Ga-As & 37.2 \\
\hline Se-Te & 44.2 & Ga-Te & 36.1 \\
\hline
\end{tabular}



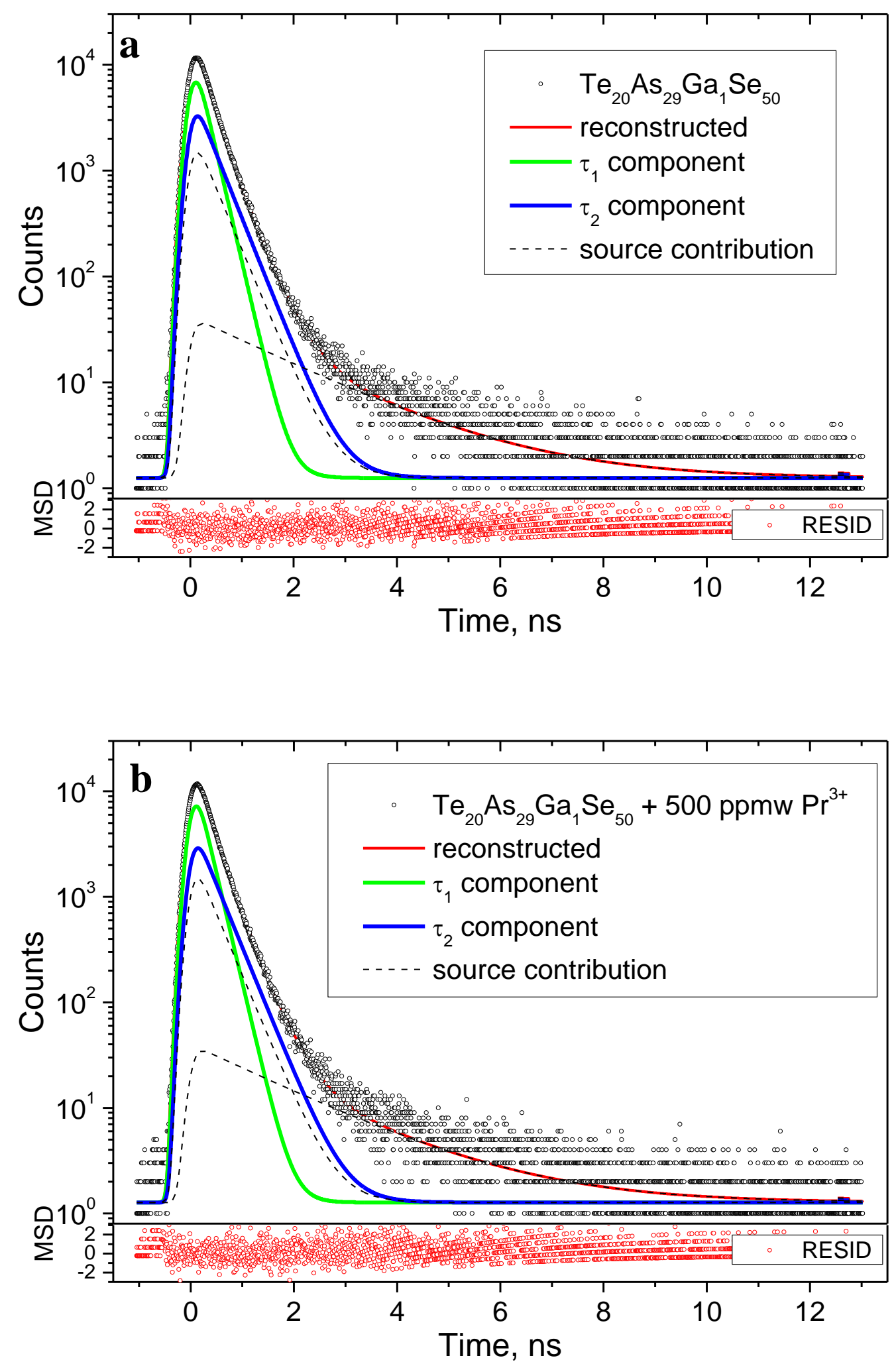

Fig. 1. Raw PAL spectra of glassy $\mathrm{Te}_{20} \mathrm{As}_{29} \mathrm{Ga}_{1} \mathrm{Se}_{50}$ (a) and $\mathrm{Te}_{20} \mathrm{As}_{29} \mathrm{Ga}_{1} \mathrm{Se}_{50}$ doped with 500 ppmw of $\operatorname{Pr}^{3+}$ (b) reconstructed from two-component fitting at the general background of source contribution (bottom inset shows statistical scatter of variance). 


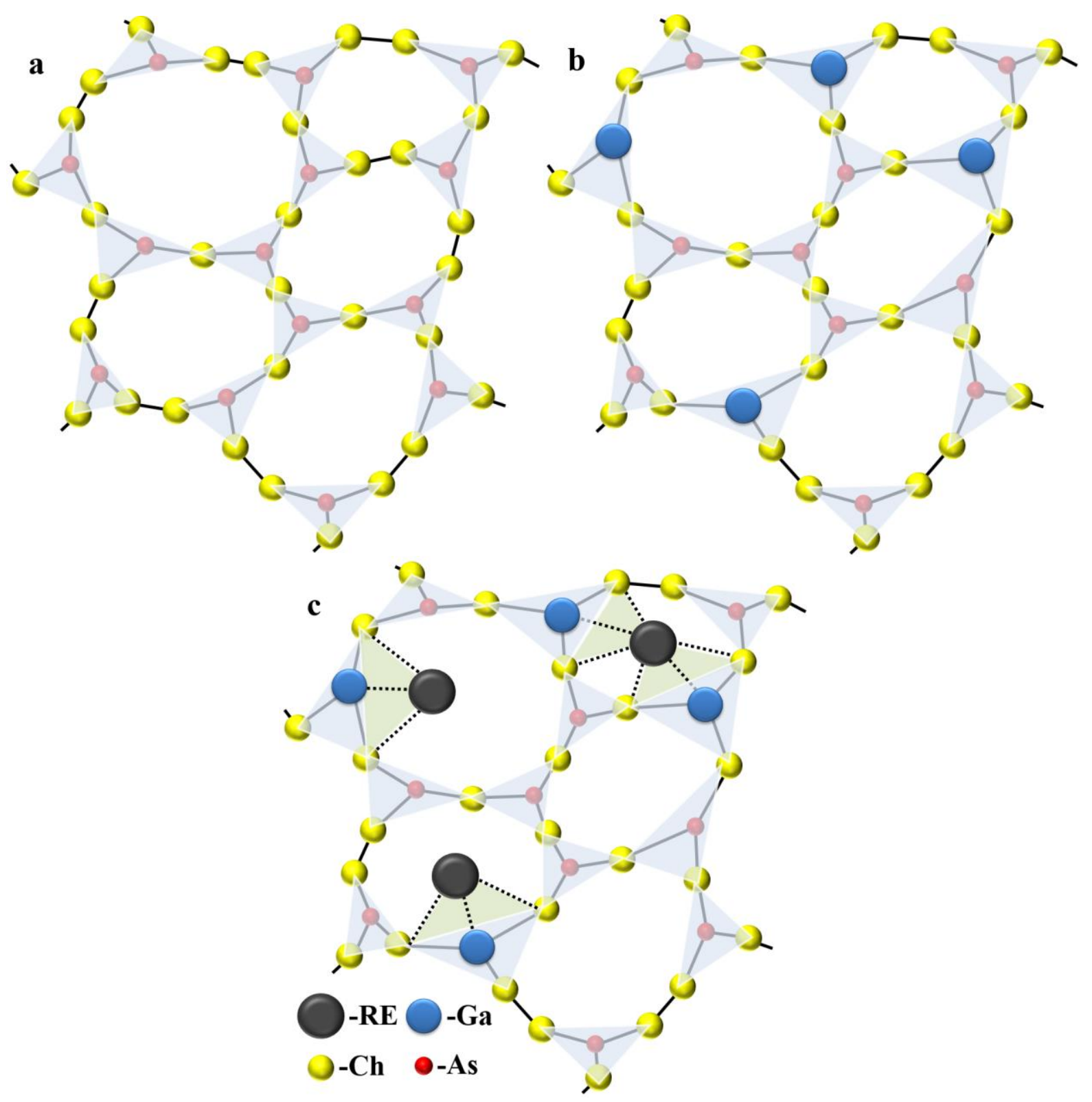

Fig. 2. Sketch of plane projection of glass structure built of $\mathrm{As}(\mathrm{Ch})_{3 / 2}$ pyramidal units interlinked by $-\mathrm{Ch}-$ or $-\mathrm{Ch}-\mathrm{Ch}-$ bridges

showing structural cycle-type arrangement with free-volume voids in Ga-free network (a),

Ga-codoped network (b) and additionally RE-modified Ga-codoped network (c). 